\title{
Technical Note: Simulation of detailed aerosol chemistry on the global scale using MECCA-AERO
}

\author{
A. Kerkweg, R. Sander, H. Tost, P. Jöckel, and J. Lelieveld \\ Air Chemistry Department, Max-Planck Institute of Chemistry, P.O. Box 3060, 55020 Mainz, Germany \\ Received: 30 January 2007 - Published in Atmos. Chem. Phys. Discuss.: 1 March 2007 \\ Revised: 16 May 2007 - Accepted: 25 May 2007 - Published: 12 June 2007
}

\begin{abstract}
We present the MESSy submodel MECCAAERO, which simulates both aerosol and gas phase chemistry within one comprehensive mechanism. Including the aerosol phase into the chemistry mechanism increases the stiffness of the resulting set of differential equations. The numerical aspects of the approach followed in MECCA-AERO are presented.

MECCA-AERO requires input of an aerosol dynamical/microphysical model to provide the aerosol size and particle number information of the modes/bins for which the chemistry is explicitly calculated. Additional precautions are required to avoid the double counting of processes, especially for sulphate in the aerosol dynamical and the chemistry model. This coupling is explained in detail.

To illustrate the capabilities of the new aerosol submodel, examples for species usually treated in aerosol dynamical models are shown. The aerosol chemistry as provided by MECCA-AERO is very sumptuous and not readily applicable for long-term simulations, though it provides a reference to evaluate simplified approaches.
\end{abstract}

\section{Introduction}

In recent years much progress has been made in incorporating aerosols into global models (Lauer et al., 2005; Stier et al., 2005; Gong et al., 2003; Spracklen et al., 2005), following the overall tendency in atmospheric modelling to include additional details of the individual processes. Many studies have focussed on the interactions of aerosols with clouds and radiation. Often these studies are based on rather simplified assumptions of the chemical composition and especially on simplifications of the uptake of gas phase species. Mostly - except for $\mathrm{H}_{2} \mathrm{SO}_{4}$ - no uptake at all (of gas phase

Correspondence to: A. Kerkweg

(akerkweg@mpch-mainz.mpg.de) species into the aerosol phase) is taken into account. Instead, only primary emissions of particle substances or aerosol categories are simulated. Thus the interactions with clouds and radiation are investigated in considerable detail, but the premises, i.e., the aerosol composition is considered in much less detail.

MECCA-AERO aims to bridge this gap (see Table 1 for a list of abbreviations and submodel names). In addition to an aerosol dynamical model which - if at all - only calculates simplified aerosol chemistry, MECCA-AERO independently and explicitly calculates non-equilibrium gas phase and aerosol phase chemistry including gas-aerosol exchange. It is a box model in its basic entity, but in this Technical Note the focus will be on its application on the global scale. Many scientific topics can only be addressed if aerosol phase chemistry is treated in more detail than currently in global aerosol dynamical models: e.g. tropospheric ozone depletion events in the Arctic (Hönninger and Platt, 2002), the bromine chemistry in the marine boundary layer (Sander et al., 2003), air quality studies etc.

MECCA-AERO, however, does not calculate aerosol dynamics/microphysics. Therefore, it requires input of an aerosol dynamical/microphysical model (in the following referred to as aerosol dynamical model or ADM): the aerosol radius, the liquid water content and the aerosol number density. MECCA-AERO uses these input parameters to calculate the reaction rates for all aerosol phase reactions. Additional precautions must be taken to prevent double counting of processes, e.g. the condensation of sulphuric acid. Recently, many new or advanced aerosol models have been developed (Gong et al., 2003; Kohonen et al., 2004; Lauer et al., 2005; Metzger et al., 2007; Spracklen et al., 2005; Stier et al., 2005), most of them applicable in global models, but to our knowledge our attempt to simulate non-equilibrium aerosol chemistry in detail in a global atmospheric chemistry general circulation model (AC-GCM) is new.

Published by Copernicus Publications on behalf of the European Geosciences Union. 
Table 1. Abbreviations.

\begin{tabular}{ll}
\hline abbreviation & \\
\hline ACM & aerosol chemistry model \\
ADM & aerosol dynamical model \\
CLOUD & MESSy submodel: large scale cloud microphysics \\
CONVECT & MESSy submodel: convection \\
CVTRANS & MESSy submodel: convective tracer transport \\
DMS & dimethyl sulphide \\
DRYDEP & MESSy submodel: \\
& dry deposition of gases and aerosol phase tracers \\
EQSAM & MESSy submodel: aerosol thermodynamics \\
KPP & Kinetic PreProcessor \\
LNOX & MESSy submodel: Lightning NO $x$ \\
LWC & liquid water content \\
M7 & MESSy submodel: aerosol dynamical model (7 modes) \\
MBL & marine boundary layer \\
MECCA & Module Efficiently Calculating the Chemistry of the Atmosphere \\
MECCA-AERO & MESSy submodel: gas phase chemistry \\
& MECCA-AEROsol \\
MESSy & submodel of MECCA: aerosol chemistry \\
MISTRA-MPIC & Modular Earth Submodel System \\
ODE & gas and aerosol phase chemistry (von Glasow 2002a,b) \\
OFFLEM & ordinary differential equation \\
ONLEM & MESSy submodel: offline emissions \\
PBL & MESSy submodel: online emissions \\
RAD4ALL & planetary boundary layer \\
ROS3 & MESSy submodel: radiation \\
SCAV & Rosenbrock solver of 3rd order \\
SEDI & MESSy submodel: SCAVenging and wet deposition \\
TROPOP & MESSy submodel: sedimentation of aerosols \\
\hline & MESSy submodel: diagnostics of tropopause, PBL height etc. \\
&
\end{tabular}

This Technical Note describes the details of the coupling between MECCA-AERO and various other submodels of the Modular Earth Submodel System (MESSy, Jöckel et al. (2005)). This may be of special interest to MESSy users only, but the challenge to combine different approaches in one complex model is more common and not only limited to MESSy.

Section 2 describes the interaction of all MESSy submodels required to simulate complex aerosol chemistry with a special focus on the coupling to the ADM. In Sect. 2.1 the formulas used to determine the aerosol phase reaction rates are given. The aerosol removal processes included in MESSy and how they are applied to the aerosol tracers of MECCAAERO are discussed in Sect. 2.2. The implementation of primary aerosol component emissions into the aerosol phase is explained in Sect. 2.3. Section 2.4 comments on the numerical pitfalls occurring by applying a complex gas and aerosol phase chemistry mechanism. To illustrate the functionality of MECCA-AERO, Sect. 3 shows results of a short term simulation including aerosol chemistry.

\section{Model description}

MECCA-AERO is an addition to the MESSy submodel MECCA (Jöckel et al., 2005; Sander et al., 2005). MECCA - without MECCA-AERO - is designed for gas phase chemistry calculations in the troposphere and the stratosphere. The core of the MECCA submodel builds upon the Kinetic PreProcessor KPP (Sandu et al., 1997a,b; Sandu and Sander, 2006). The gas phase chemistry included in MECCA as well as the technical details of the aerosol chemistry of MECCAAERO are described by Sander et al. (2005). Note that MECCA-AERO is a generalised version of the previous submodel MECCA-MBL (Sander et al., 2005) which only considered aerosols in the MBL. Additionally, in the supplement of Sander et al. (2005) a prior version of sulphate coupling is described, which has been improved since. MECCAAERO represents an extension of MECCA to calculate gas and aerosol phase chemistry simultaneously with the same mechanism. MECCA-AERO includes additional equations and species covering liquid phase and gas-liquid phase transition reactions and calculates all coefficients required for 
computation of aqueous phase chemistry. (Note: to achieve optimal consistency between the different MESSy submodels, the submodel SCAV (Tost et al., 2006) uses the same KPP equation file for liquid phase chemistry calculations as MECCA-AERO.) The liquid phase reaction mechanism is based on the work of von Glasow et al. (2002a,b) with the column model MISTRA-MPIC. Note that MECCA-AERO does not account for ion activity effects, which can affect reaction rates and equilibrium constants including gas-aerosol partitioning of semi-volatile components. But as the activity coefficients for such complex ion mixtures (easily comprising more than 20 ions) are unknown, the assumption is made that all activity coefficients are equal to 1 . There are approaches which account for activity coefficients e.g. the Equilibrium Simplified Aerosol Model (EQSAM; Metzger et al. (2007, 2002)). As EQSAM is also part of the MESSy system we plan to combine the approaches of MECCAAERO and EQSAM.

The aerosol size distribution is assumed to be constant within the MECCA(-AERO) box model (Sander et al., 2005) and in global simulations it is calculated by an aerosol submodel, e.g. M7 and exported via the MESSy data transfer/export interface into MECCA-AERO. M7 is an ADM simulating the aerosol distribution for 7 lognormal modes. 4 modes are regarded as soluble modes, 3 modes contain only insoluble material (Vignati et al., 2004). Therefore, MECCA-AERO depends on the input from an ADM.

Most ADMs only take the major aerosol compounds into account. They are based on simplified assumptions e.g., all sulphur or nitric acid entering the aerosol phase instantaneously becomes sulphate or nitrate, respectively. On the basis of these simplifications the uptake of water is determined. The calculation of the water uptake would be more accurate if the exact ionic composition of the aerosol phase would be known. The more complex information about the ionic composition is available in MECCA-AERO, thus it is possible to provide an estimate of the error caused by the simplified ADM through a comparison of the results of MECCA-AERO and the ADM.

Some overlap between the explicitly calculated gas phase and aerosol phase chemistry in MECCA-AERO and the ADM exists. This is - in case of M7 - the uptake of sulphuric acid from the gas phase into the aerosol phase. For ADMs which take more aerosol species into account, e.g., nitrate, the overlap exists also for these species. As we focus on the coupling to the ADM M7 here, we describe in the following the approach for sulphuric acid, which is, nevertheless, applicable for other species in the same way. To avoid double counting of the condensation of sulphuric acid the exchange reaction for $\mathrm{H}_{2} \mathrm{SO}_{4}$ can be switched off individually in MECCA-AERO. But as the aerosol compound tracer of the ADM and the tracers of the aerosol chemistry model (ACM) MECCA-AERO are a priori independent, the uptake of $\mathrm{H}_{2} \mathrm{SO}_{4}$ determined by the ADM must also be taken into account for the aerosol in the chemistry submodel. Thus, the sulphate tendencies are not only applied to the ADM sulphate tracer, but also to the aerosol phase sulphuric acid tracer $\mathrm{H}_{2} \mathrm{SO}_{4}$ of MECCA-AERO. Note that ADMs do normally not differentiate between the different dissociation states of sulphuric acid in the aerosol phase; sulphur entering the aerosol phase is usually regarded as bulk sulphate. This is different in MECCA-AERO, as all states of $\mathrm{S}(\mathrm{VI})\left(\mathrm{H}_{2} \mathrm{SO}_{4}, \mathrm{HSO}_{4}^{-}\right.$, $\mathrm{SO}_{4}^{2-}$ ) are distinguished. In MECCA-AERO the sulphate tendency calculated by the ADM is applied to the aerosol phase sulphuric acid tracer $\mathrm{H}_{2} \mathrm{SO}_{4}$ of MECCA-AERO. This is mandatory to maintain the ion balance and to simulate the $\mathrm{pH}$ prognostically. To keep the sulphate chemistry of the $\mathrm{ADM}$ and that of the aerosol chemistry model consistent, the sulphate of the ADM is set to the sum of the $\mathrm{S}(\mathrm{VI})$ tracers of MECCA-AERO $\left(\mathrm{H}_{2} \mathrm{SO}_{4}, \mathrm{HSO}_{4}^{-}, \mathrm{SO}_{4}^{2-}\right)$. More details are described in Sect. 2.2.

\subsection{Reaction rate coefficients}

The exchange coefficients are determined in each grid box before the KPP-integration. The forward $\left(k_{\mathrm{ex}}^{\mathrm{f}}\right.$ in $\left.1 / \mathrm{s}\right)$ and backward $\left(k_{\mathrm{ex}}^{\mathrm{b}}\right.$ in $\left.1 / \mathrm{s}\right)$ exchange rates for a species $\mathrm{X}$ between gas and aerosol phase are (Schwartz, 1986; Sander, 1999):

$k_{\mathrm{eX}}^{\mathrm{f}}(\mathrm{X})=k_{\mathrm{mt}}(\mathrm{X}) \times \mathrm{LWC}$

$k_{\mathrm{ex}}^{\mathrm{b}}(\mathrm{X})=k_{\mathrm{mt}}(\mathrm{X}) /\left(k_{\mathrm{H}}(\mathrm{X}) R T\right)$.

$k_{\mathrm{mt}}(\mathrm{X})$ (in $\mathrm{m}^{3}($ air $) /\left(\mathrm{m}^{3}(\mathrm{aq}) \mathrm{s}\right)$ ) denotes the mass transfer coefficient, $k_{\mathrm{H}}(\mathrm{X})$ is the Henry's Law coefficient of species $\mathrm{X}$ (in $\mathrm{mol} /\left(\mathrm{m}^{3}(\mathrm{aq}) \mathrm{Pa}\right)$ ), $R=8.31441 \mathrm{~J} /(\mathrm{mol} \mathrm{K})$ is the universal gas constant, LWC the liquid water content in $\mathrm{m}^{3}(\mathrm{aq}) / \mathrm{m}^{3}$ (air) and $T$ is the temperature (in $\mathrm{K}$ ).

The mass transfer coefficient $k_{\mathrm{mt}}(\mathrm{X})$ for species $\mathrm{X}$ into a single particle with radius $r$ is given by

$k_{\mathrm{mt}}(\mathrm{X})=\left(\frac{r^{2}}{3 D_{g}(\mathrm{X})}+\frac{4 r}{3 \bar{v}(\mathrm{X}) \alpha(\mathrm{X})}\right)^{-1}$

with $D_{g}(\mathrm{X})$ (in $\mathrm{m}^{2} / \mathrm{s}$ ) denoting the gas phase diffusion coefficient, $\bar{v}$ the mean molecular speed in $\mathrm{m} / \mathrm{s}$ and $\alpha$ the dimensionless accommodation coefficient (see Table 2 of mecca-aeronism.pdf in the supplement http://www.atmos-chem-phys.net/7/2973/2007/ acp-7-2973-2007-supplement.zip). $D_{g}(\mathrm{X})$ can be approximated following the kinetic gas theory (see e.g. Wayne, 2000) as $D_{g}(\mathrm{X})=\lambda_{\text {air }} \bar{v}(\mathrm{X}) / 3$ with $\lambda_{\text {air }}$ (in $\mathrm{m}$ ) being the mean free path of air molecules. The mean molecular speed is given by $\bar{v}(\mathrm{X})=\sqrt{8 R T /(\pi M(\mathrm{X}))}$, where $M(\mathrm{X})$ is the molar mass of species $X$ (in $\mathrm{kg} / \mathrm{mol}$ ).

For the aerosol microphysical properties we assume a lognormal shape of the aerosol size distribution:

$$
\frac{\mathrm{d} \tilde{N}}{\mathrm{~d} \lg (r)}=\frac{N}{\sqrt{2 \pi} \lg (\sigma)} \times \exp \left(-\frac{\left(\lg (r)-\lg \left(r_{N}\right)\right)^{2}}{2(\lg (\sigma))^{2}}\right) .
$$

The required input parameters are the particle number density $N\left(1 / \mathrm{m}^{3}\right)$, the median radius of the mode $\left(r_{N}\right)$, which 


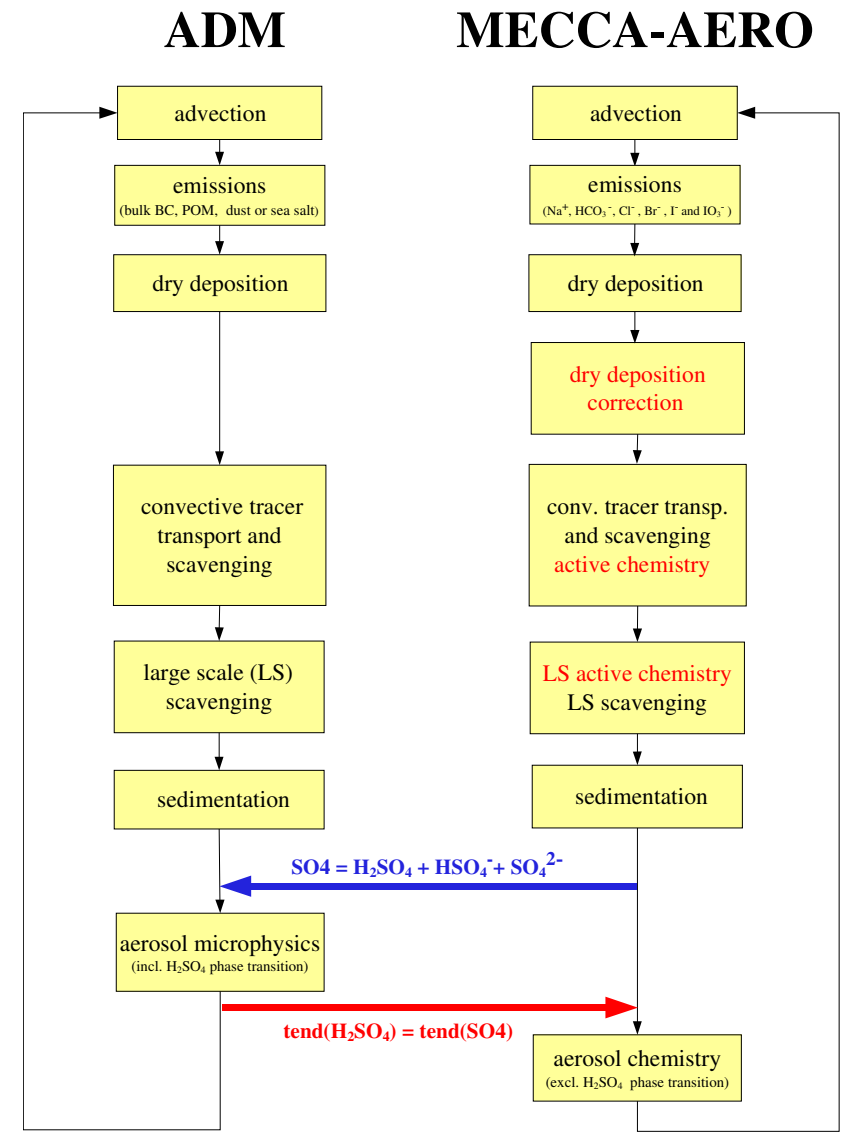

Fig. 1. Flux diagram of processes affecting tracers of the aerosol dynamical model (ADM) and MECCA-AERO. Most of the processes are applied independently for the individual tracers. The active chemistry calculations in convective and large scale clouds and precipitation (red) are omitted for the tracers of the ADM. Interactions between the sulphate tracers take place before and after the aerosol microphysical calculations. Additionally, a correction term for sea salt ion emissions is introduced into MECCA-AERO.

in our case can be the dry radius $r_{\text {dry }}$ or the ambient radius $r_{\mathrm{amb}}(\mathrm{m})$, and the standard deviation $\sigma$ of the radius distribution of the mode. At present, MECCA-AERO is designed to calculate chemistry for one or two aerosol modes.

The liquid water content of an aerosol mode $j$ is given by

$\mathrm{LWC}_{j}=\frac{4}{3} \pi\left(r_{j, \mathrm{amb}}^{3}-r_{j, \mathrm{dry}}^{3}\right) N_{j} \exp \left(\frac{9\left(\lg \sigma_{j}\right)^{2}}{2(\lg e)^{2}}\right)$

(see Sander (1999), Eq. 105). $N_{j}$ is the total number of particles in mode $j$.

Note that the LWC is used but not changed by MECCAAERO. As the liquid phase reactions depend on the size and the LWC of the aerosol, the result of MECCA-AERO very much depends on the method by which the water uptake is calculated from the ADM. The best way would be to take all ions distinguished within MECCA-AERO into account for the water uptake calculations. This may be possible in future within MESSy by a coupling between EQSAM and MECCA-AERO.

The averaged mass transfer coefficient for a modal aerosol distribution $\bar{k}_{\mathrm{j}, \mathrm{mt}}$ is an integral over the particle radius (compare e.g. Sander (1999), Eq. 113):

$$
\begin{aligned}
\bar{k}_{\mathrm{j}, \mathrm{mt}}(\mathrm{X}) & =\frac{4 \pi}{3 \mathrm{LWC}_{j}} \times \\
& \int_{-\infty}^{+\infty}\left(\frac{r_{j}^{2}}{3 D_{g}(\mathrm{X})}+\frac{4 r_{j}}{3 \bar{v}(\mathrm{X}) \alpha(\mathrm{X})}\right)^{-1} r_{j}^{3} \frac{\partial N_{j}}{\partial \lg r_{j}} \mathrm{~d} \lg r_{j} .
\end{aligned}
$$

Note: For the application in the KPP-equation set as given in MECCA-AERO, $\bar{k}_{\mathrm{j}, \mathrm{mt}}$ is given in units of $\mathrm{m}^{3}$ (air) $/\left(\mathrm{m}^{3}(\mathrm{aq}) \mathrm{s}\right)$. An analytical solution for this integral does not exist. The numerical integration would be computationally too "expensive" as this integral must be solved for each species undergoing phase transition in each grid box. Thus, MECCA-AERO calculates the mass transfer coefficient at the ambient median radius of the mode, and then scales it using a scaling factor $f_{j}$. Although this scaling factor depends on several parameters, we use 0.8 and 0.6 as an approximation for the accumulation and the coarse mode, respectively:

$\tilde{k}_{j, \mathrm{mt}}(\mathrm{X})=f_{j} \frac{\bar{v}(\mathrm{X})}{r_{j}}\left(\frac{r_{j}}{\lambda_{\text {air }}}+\frac{4}{3 \alpha(\mathrm{X})}\right)^{-1}$.

These scaling factors are only valid for the size distribution as defined by the ADM M7. For other size distributions (i.e., other $\sigma$ or radii intervals) they have to be recalculated.

A summary of all reactions included in the aqueous phase mechanism with references for the respective reaction rates is part of the electronic supplement http://www.atmos-chem-phys.net/7/2973/2007/ acp-7-2973-2007-supplement.zip.

\subsection{Removal of aerosol components}

Three physical removal processes for aerosol tracers are considered: dry deposition, sedimentation and scavenging by clouds and precipitation. Figure 1 gives a flowchart showing all processes in a comprehensive model simulation changing the tracers of an ADM and MECCA-AERO, respectively. For all these removal processes the physical aerosol properties (aerosol density, the ambient radius and the standard deviation for lognormal distributions) must be known. As MECCA-AERO does not provide this information itself, each chemical aerosol tracer is assigned to an aerosol mode as provided by an ADM. The technical realisation within MESSy is described in the Appendix. For each of the aerosol modes provided by the ADM dry deposition and sedimentation are determined by calculating a dry deposition or sedimentation velocity, respectively. Afterwards these removal velocities are applied to the chemical tracers associated with the respective aerosol modes. 
The scavenging calculation also uses the physical properties of the ADM mode the ACM tracers is associated to (Tost et al., 2006). SCAV simulates scavenging and cloud and precipitation liquid phase chemistry explicitly. For this, the ions of all available aerosol classes (bin or mode) are incorporated into the droplets when nucleation or impaction scavenging takes place. These aerosol constituents and gas phase species taken up into the cloud droplets undergo liquid phase reactions. When the cloud evaporates, the ions are transferred from the liquid phase to the largest available aerosol size class.

Sulphuric acid is one of the most important species driving liquid phase chemistry. In-cloud oxidation of $\mathrm{SO}_{2}$ to $\mathrm{S}(\mathrm{VI})$ is the main source of dissolved sulphate (Warneck, 1999; Tost et al., 2007). It leads to a substantial production of aerosol sulphate through cloud evaporation. This requires a special coupling between the sulphate tracer of the ADM and the $\mathrm{ACM}$, respectively. In principle, these tracers are treated separately, i.e. the aerosol phase of the ADM is not directly coupled to the aerosol phase of the ACM. As these aerosol phases in the model then exist in parallel, the sum of all sulphur containing aerosol tracers in the MESSy system would yield unrealistic sulphur concentrations.

This is not problematic for those processes impacting each aerosol tracer independently, e.g. dry deposition, sedimentation, advection or convective tracer transport. In contrast, however, the chemistry schemes of MECCA-AERO and SCAV and the ADM require some special treatment. As explained in the main part of Sect. 2, the overlap between MECCA-AERO and the ADM is solved by excluding the $\mathrm{H}_{2} \mathrm{SO}_{4}$ phase transition reaction in MECCA-AERO and by applying the tendency calculated by the ADM for bulk sulphate also to the aerosol chemistry tracer $\mathrm{H}_{2} \mathrm{SO}_{4}(\mathrm{j})$.

Even more complicated is the treatment of sulphate tracers in cloud and precipitation chemistry. As stated above, in-cloud oxidation is a main source for S(VI). Thus it is essential to include this process into both independently calculated aerosol phases. However, there is only one liquid phase. Including all available aerosol sulphate into this phase would double the amount of sulphate, as the chemistry scheme itself does not distinguish different aerosol phases. Furthermore, by evaporation all sulphate is transferred back into one of the two aerosol phases, which leads to an artificial increase/source in sulphate for one aerosol phase and an artificial sink for the other. This needs to be resolved by including only one of the two aerosol phases into the active chemistry scheme. We decided to treat the MECCAAERO tracers within SCAV, as MECCA-AERO represents the more detailed chemistry scheme (i.e. $\mathrm{H}_{2} \mathrm{SO}_{4}, \mathrm{HSO}_{4}^{-}$, and $\mathrm{SO}_{4}^{2-}$ are distinguished in the ACM instead of the bulk $\mathrm{SO}_{4}$ in the ADM). Choosing the bulk ADM sulphate tracers to be included into the SCAV chemistry scheme would lead to unnecessary loss of information. But as in-cloud oxidation is an important source of sulphate, it should not be ne- glected. In order to retain consistency between the two separate aerosol sulphate tracers the bulk sulphate aerosol tracer of the ADM is set to the sum of the MECCA-AERO tracers $\mathrm{H}_{2} \mathrm{SO}_{4}, \mathrm{HSO}_{4}^{-}$and $\mathrm{SO}_{4}^{2-}$. This is done in each time step before the ADM calculations. The sulphate coupling as well as the mostly independent treatment of the tracers of the ADM and the ACM MECCA-AERO, respectively, are illustrated in Fig. 1.

\subsection{Emission of primary aerosol components}

\subsubsection{Emission of aerosol components into tracers of the} chemistry model

Primary aerosol emissions in global applications of ADMs usually include bulk organic carbon and black carbon, dust and sea salt. At present the composition of these compounds is often not specified for use in an explicit chemistry model (e.g. MECCA-AERO). A detailed chemical specification of these compounds will be addressed in the future, including particle organic matter (POM), black carbon (BC) and dust.

Since the composition of sea water is well known, emissions of its components due to sea salt emission are implemented. Emissions for carbonaceous compounds and for dust particles as well as primary sulphate emissions can be easily included accordingly when their composition and the chemical reactions as well as the emission source itself are specified.

The usual assumption within ADMs is that sea salt aerosol consists of sodium chloride $(\mathrm{NaCl})$. MECCAAERO calculates the chloride emission flux $\left(F_{\mathrm{Cl}^{-}}\right.$in $\left.\operatorname{mol}\left(\mathrm{Cl}^{-}\right) /\left(\mathrm{m}^{2} \mathrm{~s}\right)\right)$ from the sea salt mass emission flux $\left(F_{\mathrm{mss}}\right.$ in $\left.\mathrm{kg}(\mathrm{NaCl}) /\left(\mathrm{m}^{2} \mathrm{~s}\right)\right)$ provided by the MESSy submodel ONLEM (Kerkweg et al., 2006b). This flux is the same as that used by the ADM to calculate sea salt emissions:

$F_{C l^{-}}=\frac{F_{\mathrm{mss}}}{M_{\mathrm{NaCl}}}$

where $M_{\mathrm{NaCl}}$ is the molar mass of sodium chloride in $\mathrm{kg} / \mathrm{mol}$. This emission flux can be either converted into

- a lower boundary condition for the vertical flux $\left(F_{\mathrm{lbc}}\right.$ in $\left(\operatorname{mol}\left(\mathrm{Cl}^{-}\right) / \operatorname{mol}(\right.$ air $\left.)\right)\left(\mathrm{kg}(\right.$ air $\left.\left.) /\left(\mathrm{m}^{2} \mathrm{~s}\right)\right)\right)$ :

$F_{\mathrm{lbc}}=F_{C l^{-}} \times M_{\mathrm{air}}$,

where $M_{\text {air }}$ is the molar mass of dry air (in $\mathrm{kg} / \mathrm{mol}$ ) or

- a tendency of the tracer mixing ratio $(\Delta \mu / \Delta t$ in $\mathrm{mol} /(\mathrm{mol} \mathrm{s}))$ :

$$
\frac{\Delta \mu}{\Delta t}=F_{C l^{-}} \times \frac{M_{\mathrm{air}}}{\Delta z \times \rho_{\mathrm{air}}}
$$

with $\Delta z=$ layer thickness (in $\mathrm{m}$ ) and $\rho_{\text {air }}=$ air density (in $\mathrm{kg} / \mathrm{m}^{3}$ ). 
Table 2. Relative ion abundance in sea water (Wilson, 1975).

\begin{tabular}{ll}
\hline Ion & $\begin{array}{l}\text { Ratio } \\
\mathrm{X}\end{array}$ \\
\hline $\mathrm{Cl}^{-}$ & 1.0 \\
$\mathrm{Br}^{-}$ & $1.5 \times 10^{-3}$ \\
$\mathrm{HCO}_{3}^{-}$ & $4.2 \times 10^{-3}$ \\
$\mathrm{I}^{-}$ & $1.38 \times 10^{-7}$ \\
$\mathrm{IO}_{3}^{-}$ & $4.84 \times 10^{-7}$ \\
\hline
\end{tabular}

In addition to chloride, sea salt consists of the anions $\mathrm{Br}^{-}$, $\mathrm{HCO}_{3}^{-}, \mathrm{I}^{-}$and $\mathrm{IO}_{3}^{-}$. These anions occur in sea water in a constant ratio to chloride (Table 2). The emission fluxes of these ions are determined by multiplying the chloride emission flux by these ratios.

The most abundant cation is sodium. As the cations do not undergo reactions in the current aerosol phase chemistry mechanism, we refrain from further differentiation. To maintain ion balance, equal amounts of cations and anions must be emitted. Thus the assumed emission flux of $\mathrm{Na}^{+}$is the sum of the emission fluxes by $\mathrm{Cl}^{-}, \mathrm{Br}^{-}, \mathrm{HCO}_{3}^{-}, \mathrm{I}^{-}$and $\mathrm{IO}_{3}^{-}$.

\subsubsection{A correction term applied to sea salt emissions}

For global simulations the correct calculation of sea salt anion emissions from the sea salt emission mass flux represents a difficult task. As explained in Sect. 2.3.1, based on the assumption that the calculated sea salt mass flux consists of $\mathrm{NaCl}$ only, the chloride emission flux is calculated from the sea salt emission mass flux, and subsequently the bromide, iodide, iodate and the hydrogen carbonate fluxes are scaled with constant factors (Table 2). This way of emission calculation bears a subtle problem: the surface wind speed triggers the wave motion of the ocean. The higher the surface wind speed, the higher are the waves and the more sea spray is produced. The droplets can undergo two different processes. The smaller ones remain airborne and equilibrate with the relative humidity of their environment. However, larger droplets sediment nearly instantaneously to the ocean, thus they do not influence the chemistry. In the model the aerosol distribution is simulated following an operator splitting approach (cf. Fig. 1): first the emission of sea salt mass and particle number is calculated from the emission flux, then the removal processes such as dry deposition, sedimentation and wet deposition are applied and finally the chemical tendencies are determined. This is done for all tracers. The consequence for the aerosol chemistry tracers is that the aerosol is fresher (or less aged) than it would be without process splitting: the ion emissions are calculated from the sea salt emission flux as explained above. These newly emitted ions are added to the chemical tracers of the aerosol. Thus a new aerosol composition is introduced and this new mixture undergoes the removal processes with the aerosol particles.
In the end the simulated aerosol is "too fresh", because in reality removal processes deposit much more fresh sea salt mass than aged sea salt mass. This has a strong effect for those species which differ significantly in their composition in aged and fresh sea salt aerosol. E.g. the emission of $\mathrm{HCO}_{3}^{-}$ adds alkalinity to the aerosol. Overestimating its emission would lead to a rise in aerosol $\mathrm{pH}$ and thus in too alkaline aerosol.

The effect of dry deposition is largest, as it is calculated directly after the emission calculation in the operator splitting sequence of our model. Thus the dry deposition accounts for a part of substance removal, which would alternatively happen through sedimentation, if the order in the operator splitting sequence would be the other way round. Therefore, a possible solution to the problem of overestimated net emissions is to calculate a correction term for the dry deposition flux resulting in an additional amount of deposited sea salt mass.

The correction term $\left(F_{\text {corr }}\right)$ for ion $\mathrm{X}$ is determined after the dry deposition tendency is already calculated in the model. As the emitted sea salt particle number linearly depends on the emitted particle mass and as the particle number is not changed by any chemical process, we use the number of freshly emitted particles $\left(N_{\text {new }}\right)$ and the sum of all particles airborne after emission calculation (but before deposition is applied, $N_{\Sigma}$ ) to scale the deposition fluxes. We assume that the deposition fluxes $F_{\text {dep }}(\mathrm{X})$ are valid for sea salt particles of the composition present before the emission calculations, whereas freshly emitted sea salt deposits according to the deposition flux of sea salt mass $\left(F_{\text {dep }}(S S)\right)$. Thus a more realistic deposition flux of ion $\mathrm{X}\left(F_{\text {real,dep }}(\mathrm{X})\right.$ in units of $(\mathrm{mol} / \mathrm{mol}) \mathrm{kg}($ air $\left.) /\left(\mathrm{m}^{2} \mathrm{~s}\right)\right)$ is therefore given by

$$
\begin{aligned}
F_{\text {realdep }}(X)= & F_{\text {dep }}(S S) \times f(\mathrm{X}) \times \frac{N_{\text {new }}}{N_{\Sigma}} \\
& +F_{\text {dep }}(\mathrm{X}) \times\left(1-\frac{N_{\text {new }}}{N_{\Sigma}}\right)
\end{aligned}
$$

where $f(\mathrm{X})$ is the factor as listed in Table 2.

Note: The tendency for the dry deposition flux is applied within MESSy before $F_{\text {realdep }}(\mathrm{X})$ is calculated, because of the operator splitting. Thus the originally calculated dry deposition flux must be added again and the newly calculated real deposition flux subtracted (as deposition is a loss process). The correcting ion deposition flux of ion $\mathrm{X}\left(F_{\text {corr }}(\mathrm{X})\right.$ in units of $(\mathrm{mol} / \mathrm{mol}) \mathrm{kg}($ air $\left.) /\left(\mathrm{m}^{2} \mathrm{~s}\right)\right)$ is therefore given by

$$
\begin{aligned}
F_{\text {corr }}(\mathrm{X}) & F_{\text {dep }}(\mathrm{X})-F_{\text {realdep }}(\mathrm{X}) \\
= & F_{\text {dep }}(\mathrm{X}) \\
& -F_{\text {dep }}(S S) \times f(\mathrm{X}) \times \frac{N_{\text {new }}}{N_{\Sigma}} \\
& -F_{\text {dep }}(\mathrm{X}) \times\left(1-\frac{N_{\text {new }}}{N_{\Sigma}}\right) \\
= & -F_{\text {dep }}(S S) \times f(\mathrm{X}) \times \frac{N_{\text {new }}}{N_{\Sigma}} \\
& +\frac{N_{\text {new }}}{N_{\Sigma}} \times F_{\text {dep }}(\mathrm{X})
\end{aligned}
$$


Since the dry deposition tendency is applied before in the sequence of operators, the first term of Eq. (11) corrects for this, the second term yields the dry deposition flux of freshly emitted sea salt particles and the third term is the dry deposition flux for aged sea salt particles. The correction flux is applied to the tracers as described for the emission fluxes in Sect. 2.3.1.

Over land, where the sea salt emission is zero the correction term is also zero, whereas the correction term leads to enhanced ion deposition in regions of high sea salt emissions over the ocean. This effect is discussed in more detail in Sect. 3.2.

\subsection{Numerical challenges with MECCA-AERO}

The KPP package provides several numerical solvers. For our calculations we have used the 3rd order Rosenbrock solver (ROS3) with adaptive time stepping. Experience has shown that it is stable for nearly all atmospheric gas phase chemistry applications. The inclusion of aerosol phase chemistry, however, leads to a very stiff set of ordinary differential equations (ODE), which sometimes can not be handled by the ROS3 solver. For example, the heterogeneous reactions

$$
\begin{aligned}
& \mathrm{N}_{2} \mathrm{O}_{5}+\mathrm{H}_{2} \mathrm{O} \rightarrow 2 \mathrm{HNO}_{3}(\mathrm{j}) \\
& \mathrm{N}_{2} \mathrm{O}_{5}+\mathrm{Cl}^{-}(\mathrm{j}) \rightarrow \mathrm{ClNO}_{2}+\mathrm{NO}_{3}^{-}(\mathrm{j}) \\
& \mathrm{N}_{2} \mathrm{O}_{5}+\mathrm{Br}^{-}(\mathrm{j}) \rightarrow \mathrm{BrNO}_{2}+\mathrm{NO}_{3}^{-}(\mathrm{j}) \\
& \mathrm{ClNO}_{3}+\mathrm{Cl}^{-}(\mathrm{j}) \rightarrow \mathrm{Cl}_{2}(\mathrm{j})+\mathrm{NO}_{3}^{-}(\mathrm{j}) \\
& \mathrm{ClNO}_{3}+\mathrm{H}_{2} \mathrm{O} \rightarrow \mathrm{HOCl}(\mathrm{j})+\mathrm{HNO}_{3}(\mathrm{j}) \\
& \mathrm{ClNO}_{3}+\mathrm{Br}^{-}(\mathrm{j}) \rightarrow \mathrm{BrCl}(\mathrm{j})+\mathrm{NO}_{3}^{-}(\mathrm{j}) \\
& \mathrm{BrNO}_{3}+\mathrm{H}_{2} \mathrm{O} \rightarrow \mathrm{HOBr}(\mathrm{j})+\mathrm{HNO}_{3}(\mathrm{j}) \\
& \mathrm{BrNO}_{3}+\mathrm{Cl}^{-}(\mathrm{j}) \rightarrow \mathrm{BrCl}(\mathrm{j})+\mathrm{NO}_{3}^{-}(\mathrm{j}) \\
& \mathrm{BrNO}_{3}+\mathrm{Br}^{-}(\mathrm{j}) \rightarrow \mathrm{Br}(\mathrm{j})+\mathrm{NO}_{3}^{-}(\mathrm{j})
\end{aligned}
$$

establish a direct exchange of different gas phase species, aerosol phase species and ions. These reactions are very fast and sometimes ROS3 is not able to handle these reactions correctly. In these cases it produces unreasonably high mixing ratios ( $>1 \mathrm{~mol} / \mathrm{mol}$ or "not a number $(\mathrm{NaN})$ "), even though automatic time stepping is used. As mentioned above, KPP provides several numerical solvers, and choosing a different solver or adjusting their settings may solve the problem. However, there are cases (e.g. at low LWC) where this is not possible, and it becomes necessary to simplify the chemical mechanism, e.g. by reduction of the aerosol chemistry to one mode, or by a reasonable reduction of the reaction equation set. MECCA-AERO has originally been designed to simulate halogen chemistry in the marine boundary layer. Thus, many bromine and iodine reactions are included in the equation file. Halogen reactions are the fastest so far included in MECCA-AERO and they significantly increase the stiffness of the differential equation set.

For model studies that do not focus on bromine and/or iodine chemistry it is possible to reduce the numerical stiff- ness considerably by switching off the reactions containing bromine and/or iodine. An understanding of processes like the influence of bromine chemistry on ozone in the marine boundary layer (Sander et al., 2003; Hebestreit et al., 1999) or bromine explosions in the Arctic spring (Solberg et al., 1996; Hönninger and Platt, 2002) can only be reached by applying a model including this chemistry in detail such as MECCA-AERO does. One of the reasons for the development of the complex chemistry mechanism in MECCAAERO was to investigate in detail the potential importance of halogen chemistry.

Chlorine is very important in view of the aerosol $\mathrm{pH}$, thus chlorine should not be neglected in aerosol chemistry simulations. However, not all reactions of chlorine may be of the same importance. This can also be tested by application of MECCA-AERO. In the list of reactions in the electronic supplement http://www.atmos-chem-phys.net/7/2973/ 2007/acp-7-2973-2007-supplement.zip those reactions labelled "Mbl" define a reduced subset of equations which give reasonable results compared to the comprehensive equation set for marine boundary layer $(\mathrm{mbl})$ studies.

The stiffness of the ODE system increases with decreasing liquid water content. For this reason the chemistry calculations in the aerosol phase are only applied if the liquid water content of the aerosol exceeds $10^{-12} \mathrm{~m}^{3}$ (aq) $/ \mathrm{m}^{3}$ (air) (for simulations including bromine chemistry). This limit is basically dictated by the stability of the solver. But it is low enough to calculated the bromine source and bromine recycling within the marine boundary layer.

To illustrate the performance of the KPP 3rd order Rosenbrock solver with automatic time stepping, Fig. 2 shows the number of resulting substeps for solving the chemistry mechanism for a typical global model time step of $12 \mathrm{~min}$. This example is taken from the simulation described in Sect. 3. The upper panel depicts the logarithm of the liquid water content (LWC) of the coarse mode aerosol in the lowest model layer. Where the LWC is higher than $10^{-12} \mathrm{~m}^{3} / \mathrm{m}^{3}$ aerosol chemistry is calculated, everywhere else only the gas phase chemistry mechanism is applied. The middle panel shows the number of substeps used by KPP to integrate the differential equation set in the lowest model layer. Obviously, the number of time steps required in grid boxes where aerosol chemistry is calculated is much higher than in grid boxes with only gas phase chemistry. Maxima of more than 220 substeps occur where aerosol chemistry equations are solved. In contrast, grid boxes where only gas phase chemistry is taken into account are usually integrated within 20 substeps. The lower panel of Fig. 2 depicts the same snapshot, but at $70 \mathrm{hPa}$ (i.e. in the stratosphere, where the presented aerosol chemistry mechanism does not play a role). Here, chemistry is most demanding in the regions of sunrise and sunset. The highest number of KPP substeps in this case is 40 , i.e. more than a factor of five less than for aerosol chemistry applications. The solver needs a minimum of 8 substeps. 

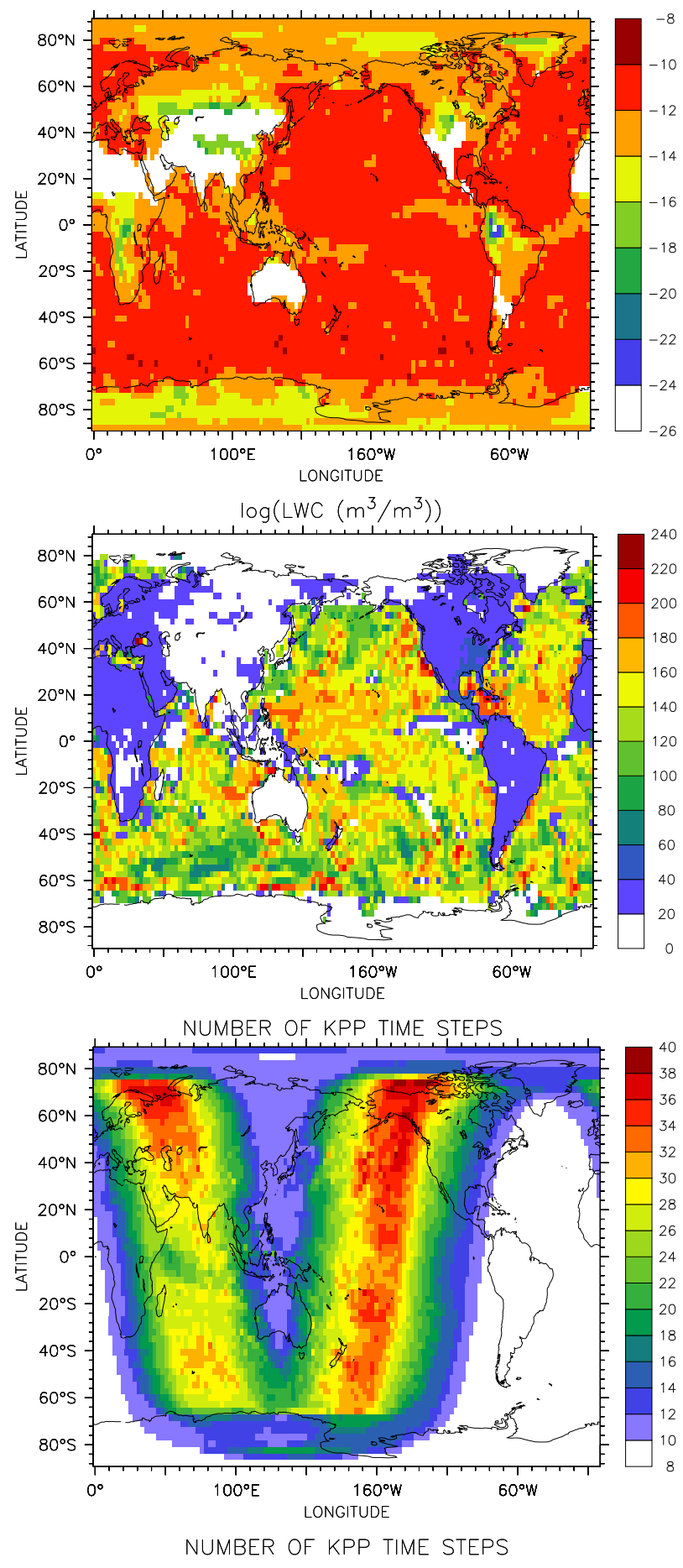

Fig. 2. Top: logarithm of the liquid water content in the lowest model layer (up to approximately $70 \mathrm{~m}$ ); Middle: number of substeps chosen by KPP in the lowest model layer where aerosol chemistry is calculated in many grid cells over the ocean; Bottom: number of substeps at a height of $70 \mathrm{hPa}$, where only gas phase chemistry is applied. Shown are snapshots for 22 April 1999, 05:00 UTC.

\section{Example}

To illustrate the capabilities of MECCA-AERO this section presents some selected results of a global model simulation.

\subsection{Simulation description}

We used the model ECHAM5/MESSy1 (E5/M1) (Roeckner et al., 2006; Jöckel et al., 2006) in the T42L31 resolution, i.e., with a corresponding quadratic Gaussian grid of $2.8^{\circ} \times 2.8^{\circ}$ and 31 layers in the vertical reaching up to $10 \mathrm{hPa}$ (middle of uppermost layer). The MESSy submodels CLOUD, CONVECT and CVTRANS were used to simulate cloud processes, convection and convective tracer transport, respectively. The submodel RAD4ALL was applied to calculate the radiation. In this study RAD4ALL is coupled to a climatology for aerosol surface area and to the online calculated mixing ratios of $\mathrm{CO}_{2}, \mathrm{O}_{3}$ and $\mathrm{CH}_{4}$. For $\mathrm{N}_{2} \mathrm{O}, \mathrm{CFCl}_{3}$, and $\mathrm{CF}_{2} \mathrm{Cl}_{2}$, prescribed mixing ratios of $306 \mathrm{nmol} / \mathrm{mol}, 280 \mathrm{pmol} / \mathrm{mol}$, and $484 \mathrm{pmol} / \mathrm{mol}$ are used, respectively. For the tracers $\mathrm{CH}_{4}$ and $\mathrm{CO}_{2}$ observed mixing ratios have been assimilated into the lowest model layer as explained in Kerkweg et al. (2006b) and Jöckel et al. (2006). The tropopause height is provided by the submodel TROPOP. Dry deposition and sedimentation are calculated by the submodels DRYDEP and SEDI (Kerkweg et al., 2006a). Cloud chemistry and scavenging are simulated using the submodel SCAV (Tost et al., 2006). Gas phase emissions of $\mathrm{NO}, \mathrm{CO}, \mathrm{CH}_{3} \mathrm{OH}, \mathrm{HCHO}, \mathrm{HCOOH}, \mathrm{NO}_{\mathrm{x}}$ (from aircraft), $\mathrm{SO}_{2}$ and $\mathrm{NH}_{3}$ are provided by OFFLEM (Kerkweg et al., 2006b; Ganzeveld et al., 2006). NO emissions from lightning (submodel LNOX) are taken into account and gas phase emissions of dimethyl sulphide (DMS, Liss and Merlivat, 1986; Kettle and Andreae, 2000) and biogenic NO (Ganzeveld et al., 2002) are calculated by ONLEM (Kerkweg et al., 2006b). ONLEM also provides the primary aerosol emissions of sea salt (Guelle et al., 2001), of black carbon and particulate organic matter as made available by AeroCom (Dentener et al., 2006) and of dust (Balkanski et al., 2003; Schulz et al., 1998). These aerosol emissions are applied by the ADM M7 (Vignati et al., 2004), and the sea salt emissions are also used by MECCA-AERO. M7 calculates the input data required by MECCA-AERO as described in the previous section. Photolysis rate coefficients, which are also required by MECCA are calculated using the method of Landgraf and Crutzen (1998) (submodel JVAL). For more information about the submodels we refer to the web-site http://www.messy-interface.org and to the E5/M1 evaluation publication (Jöckel et al., 2006). For MECCAAERO, a mechanism excluding bromine and iodine chemistry has been chosen. The chosen mechanism is also part of the supplement http://www.atmos-chem-phys.net/7/2973/ 2007/acp-7-2973-2007-supplement.zip. The model was integrated for three years. In the following, annual averages of the third year are shown. 

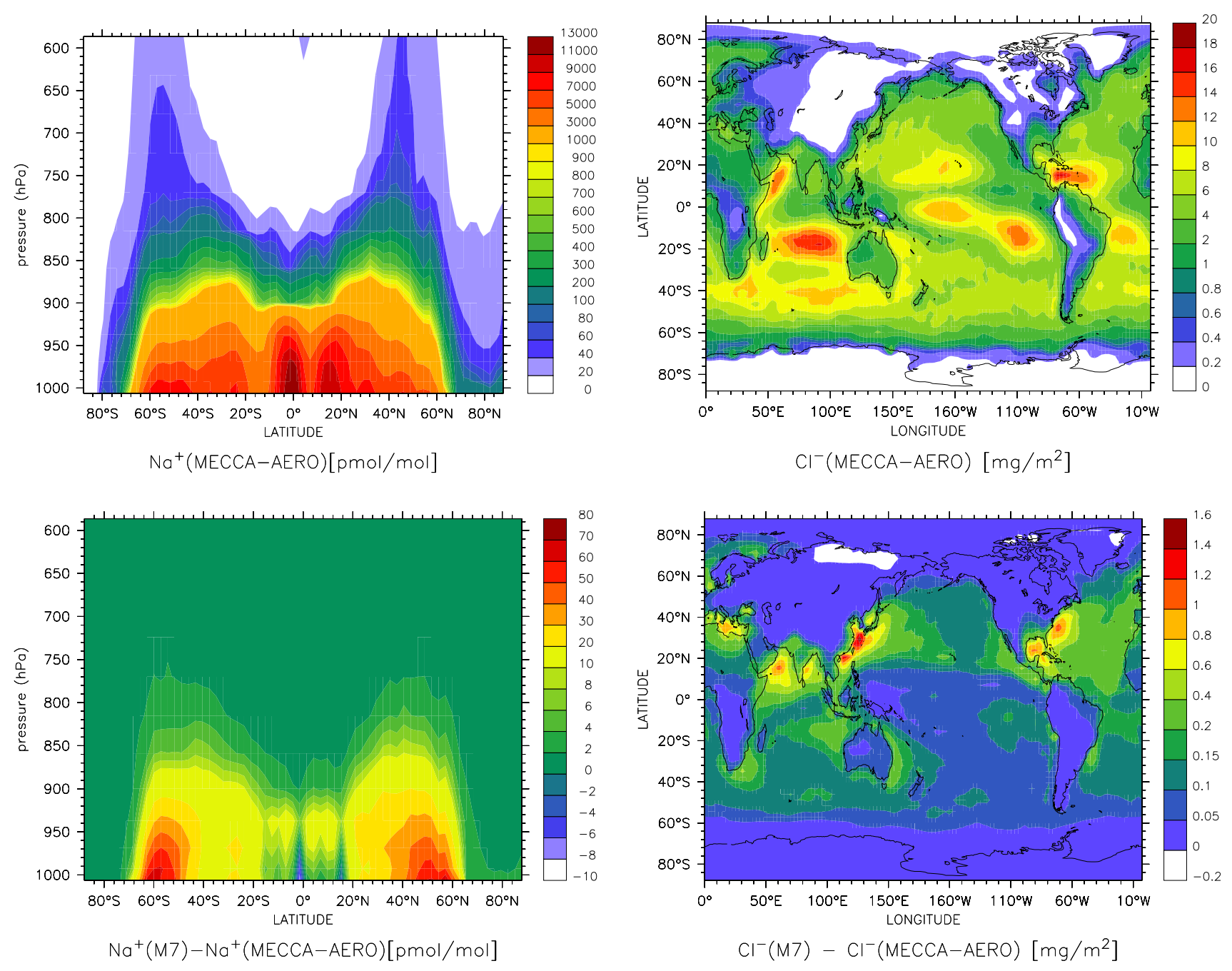

Fig. 3. Left top: Annual average $\mathrm{Na}^{+}$mixing ratios (in pmol/mol) calculated by MECCA-AERO for $180^{\circ}$ West. Left bottom: Annual average difference of $\mathrm{Na}^{+}$mixing ratios (in pmol/mol) calculated by M7 and MECCA-AERO for $180^{\circ} \mathrm{W}$. Right top: Annual average burden (in $\mathrm{mg} / \mathrm{m}^{2}$ ) of $\mathrm{Cl}^{-}$calculated by MECCA-AERO. Right bottom: Difference of annual average burdens (in $\mathrm{mg} / \mathrm{m}^{2}$ ) of $\mathrm{Cl}^{-}$calculated by M7 and MECCA-AERO, respectively.

\subsection{Example results}

To demonstrate the capabilities of MECCA-AERO we focus on species distinguished within ADMs.

The bottom panel on the left hand side of Fig. 3 displays the difference of the $\mathrm{Na}^{+}$mixing ratio for the coarse mode aerosol as calculated from the M7 sea salt tracer to the MECCA-AERO tracer $\mathrm{Na}^{+}$. Counteracting processes cause differences in the $\mathrm{Na}^{+}$tracers of these two models. On the one hand, the $\mathrm{Na}^{+}$emission flux of MECCA-AERO is larger, as the $\mathrm{Na}^{+}$emission flux equals the sum of the anion emissions (see Sect. 2.3.1), where the $\mathrm{Na}^{+}$emission flux equals only the $\mathrm{Cl}^{-}$emission flux for M7. The effect of higher emissions in MECCA-AERO is negligibly small, as the ratios of all other anions are smaller than for chloride by three orders of magnitude (cf. Table 2). On the other hand, the effec- tive emission fluxes differ because of the correction terms applied to the MECCA-AERO $\mathrm{Na}^{+}$emission. Above approximately $750 \mathrm{hPa}$ altitude no differences are distinguishable. The largest differences are apparent around $60^{\circ} \mathrm{S}$ and $55^{\circ} \mathrm{N}$. These are the regions with highest wind speeds. There, the correction term applied for direct ion emissions determined from sea salt emissions (as described in Sect. 2.3.2) becomes most important, as higher wind speeds mean higher emission fluxes and emission of larger aerosol particles which also deposit much faster (see Sect. 2.3.2). Thus the bottom left panel in Fig. 3 mainly reflects the effects of this correction term. However, compared to the absolute values as shown in the upper panel, this effect is minor in the case of $\mathrm{Na}^{+}$. It becomes important when looking at species which can be largely depleted in the aerosol phase, e.g. bromine. This 

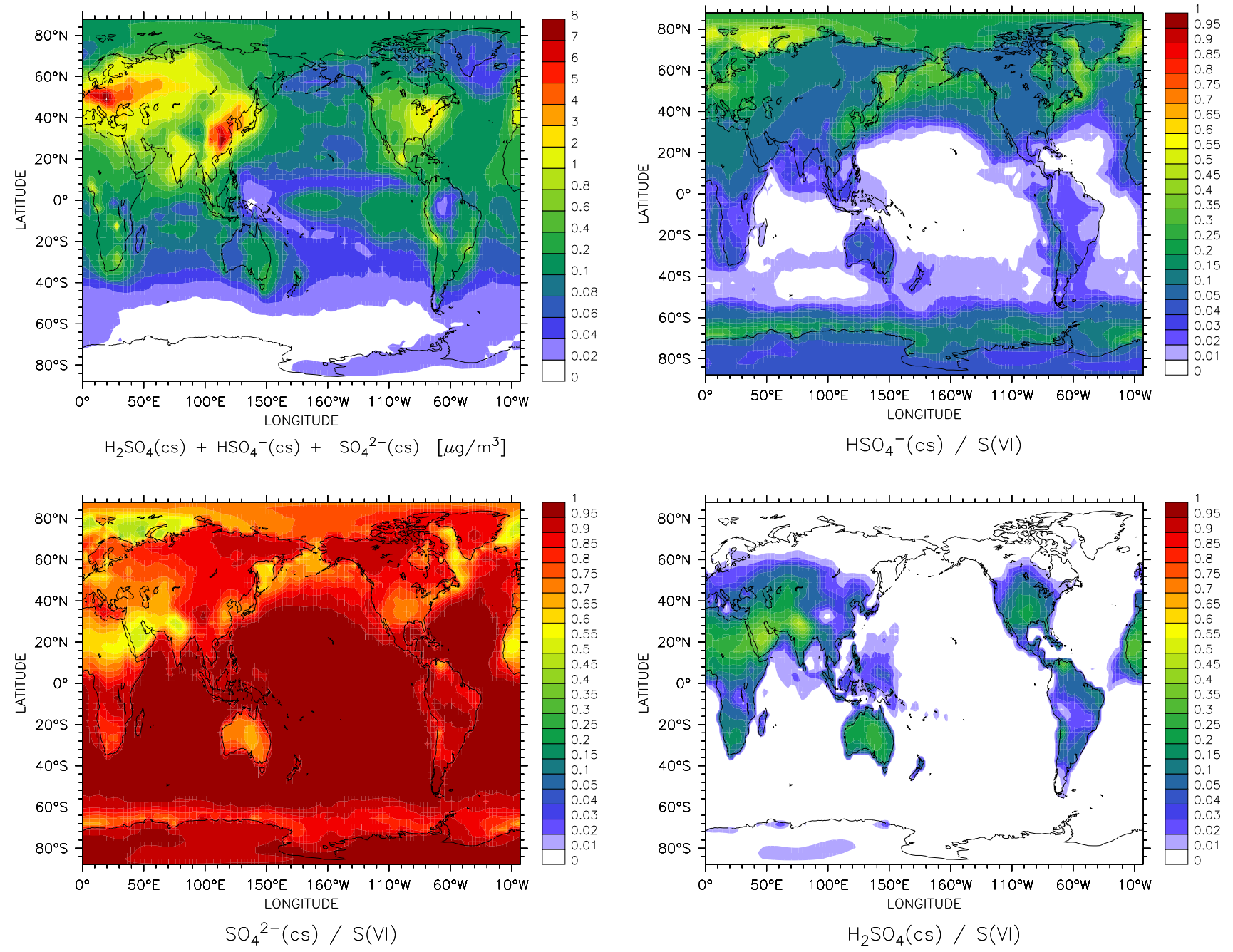

Fig. 4. Upper left: Annual average concentration (in $\mu \mathrm{g} / \mathrm{m}^{3}$ ) of sulphur VI ( $\mathrm{S}(\mathrm{VI})$ ) in the lowest model layer. The other panels show the fractions of the individual $\mathrm{S}(\mathrm{VI})$ compounds $\left(\mathrm{HSO}_{4}^{-}, \mathrm{SO}_{4}^{2-}\right.$ and $\left.\mathrm{H}_{2} \mathrm{SO}_{4}\right)$.

will be illustrated in upcoming papers focussing on bromine chemistry.

The right hand side of Fig. 3 shows an example for chlorine. As chlorine can be depleted in highly acidified aerosols, the effect of the correction term is larger than for $\mathrm{Na}^{+}$. The bottom panel depicts the difference of the annually averaged burdens of chlorine in sea salt as calculated by M7 minus the burden of $\mathrm{Cl}^{-}$calculated by MECCA-AERO. Here, the largest differences occur in heavily polluted regions, i.e. east of China and at the east coast of North America. The Mediterranean and the northern part of the Indian Ocean also show some differences. The absolute values calculated by MECCA-AERO shown in the upper panel reveal the higher significance for the applied correction for chlorine compared to $\mathrm{Na}^{+}$. The lower column densities of the MECCA-AERO tracer result mainly from depletion of chloride which takes place in highly acidified aerosol in polluted regions. This process is included in the MECCA-AERO chemistry scheme, but it is neglected in ADMs. This might be of special interest for highly polluted coastal areas, e.g. the North American east coast or the Chinese coast. MECCAAERO provides a tool to investigate the chemistry of these areas in more detail.

ADMs usually treat $\mathrm{S}(\mathrm{VI})$ as a bulk species and assume it to be completely in the form of $\mathrm{SO}_{4}^{2-}$. Figure 4 depicts the overall sulphur $\mathrm{S}(\mathrm{VI})$ concentration for coarse mode aerosol as given by the sum of the $\mathrm{H}_{2} \mathrm{SO}_{4}, \mathrm{HSO}_{4}^{-}$, and $\mathrm{SO}_{4}^{2-}$ tracer in the lowest model layer. The other three panels show the fraction of the individual components. Obviously, by far the largest part $(95-100 \%)$ is in form of $\mathrm{SO}_{4}^{2-}$. Only in strongly polluted regions, where the aerosol is highly acidic, the contributions of $\mathrm{H}_{2} \mathrm{SO}_{4}$ and $\mathrm{HSO}_{4}^{-}$are substantial. The relatively high fractions of $\mathrm{H}_{2} \mathrm{SO}_{4}$ and $\mathrm{HSO}_{4}^{-}$over dry continental regions result from the fact that nucleation 
and condensation of $\mathrm{H}_{2} \mathrm{SO}_{4}$ calculated by the ADM M7 still occur and the liquid phase production of $\mathrm{S}(\mathrm{VI})$ is small in these environments.

This in turn shows that some important chemical processes are neglected by the assumption of bulk aerosol sulphate. Further model studies with MECCA-AERO may reveal such processes.

\section{Summary}

MECCA-AERO is an ideal complement to less explicit schemes which have to be used in long-term simulations, but it is very sumptuous, and, depending on the chosen reaction setup, numerical instabilities can occur.

Some important scientific questions can only be addressed with explicit chemistry schemes such as MECCA-AERO; Examples are bromine explosion events in the Arctic, halogen chemistry in the marine boundary layer, and aerosol acidity calculations. Furthermore, aerosol chemistry may have a major influence in polluted coastal regions as the North-American East coast or the east coast of China. Advances in air pollution chemistry research in such areas will benefit from including more detailed aerosol phase chemistry (as described by MECCA-AERO).

As part of the community model MESSy, MECCA-AERO is available upon request. For detailed information see http: //www.messy-interface.org.

\section{Appendix A}

\section{Application of dry deposition and sedimentation velocities in MESSy}

The coupling of MECCA-AERO to the removal processes dry deposition and sedimentation, which are calculated by the MESSy submodels DRYDEP and SEDI (Kerkweg et al., 2006a), is similar in both cases. These submodels analyse the TRACER (Jöckel et al., in prep) meta-information structure checking if a tracer is of medium AEROSOL, if the respective processes are required for this tracer (i.e. ndrydep or nsedi set to ON) and if the aerosol submodel (the tracer is associated with) is active. Note that an aerosol tracer always gets two "submodel markers". The first one indicates which submodel defined this tracer. The identification part of the meta-information structure holds this information in the keyword submodel, e.g., submodel="mecca" in case of a tracer defined by MECCA(-AERO). In addition, the TRACER meta-information structure contains a section in which the aerosol properties are defined (med_aerosol); i.e., the name of the submodel the aerosol tracer is associated with (med_aerosol\%modelname), the method (modal or bin) of the associated aerosol model (med_aerosol\%method) and the mode/bin the aerosol tracer (med_aerosol\%mode) is associated with. For example, a tracer defined by MECCAAERO is associated to the soluble coarse mode of the aerosol submodel M7, and in this case the settings are: med_aerosol\%modelname="m7", med_aerosol\%method=modal and med_aerosol\%mode $=4$. For this tracer all removal processes are applied, as if the tracer would be a tracer of the soluble coarse mode of the submodel M7. For DRYDEP and SEDI this means that the dry deposition velocity or the terminal velocity calculated for the soluble coarse mode of M7 are also applied to this tracer. Additional details are given in the Technical Note about DRYDEP and SEDI (Kerkweg et al., 2006a).

Acknowledgements. Many thanks to A. Sandu (Virginia Tech) for developing (and continuously improving) KPP. We have used the Ferret program (http://www.ferret.noaa.gov) from NOAA's Pacific Marine Environmental Laboratory for creating some of the graphics in this paper. One of us (A.K.) acknowledges the receipt of the "Paul Crutzen Nobelpreisträger-Stipendium" of the Max-Planck-Society. We thank all our MESSy co-developers.

Edited by: M. Dameris

\section{References}

Balkanski, Y., Schulz, M., Claquin, T., Moulin, C., and Ginoux, P.: Global emissions of mineral aerosol: Formulation and validation using satellite imagery, chap. Emission of Atmospheric Tracer Compounds, pp. 253-282, Kluwer Acad., Norwell, Mass., 2003.

Dentener, F., Kinne, S., Bond, T., Boucher, O., Cofala, J., Generoso, S., Ginoux, P., Gong, S., Hoelzemann, J. J., Ito, A., Marelli, L., Penner, J. E., Putaud, J.-P., Textor, C., Schulz, M., van der Werf, G. R., and Wilson, J.: Emissions of primary aerosol and precursor gases in the years 2000 and 1750 prescribed data-sets for AeroCom, Atmos. Chem. Phys., 6, 4321-4344, 2006, http://www.atmos-chem-phys.net/6/4321/2006/.

Ganzeveld, L., Lelieveld, J., Dentener, F., Krol, M., and Bouwman, A. J.: Global soil-biogenic $\mathrm{NO}_{\mathrm{x}}$ emissions and the role of canopy processes, J. Geophys. Res., 107, 4298, doi:10.1029/2001JD001289, 2002.

Ganzeveld, L., Aardenne, J., Butler, T., Lawrence, M., Metzger, S., Stier, P., Zimmermann, P., and Lelieveld, J.: Anthropogenic and natural offline emissions and the online EMission and dry DEPosition submodel EMDEP of the Modular Earth Submodel System (MESSy, Atmos. Chem. Phys. Discuss., 6, 5457-5483, 2006,

http://www.atmos-chem-phys-discuss.net/6/5457/2006/.

Gong, S. L., Barrie, L. A., Blanchet, J.-P., von Salzen, K., Lohmann, U., Lesins, G., Spacek, L., Zhang, L. M., Girard, E., Lin, H., Leaitch, R., Leighton, H., Chylek, P., and Huang, P.: Canadian Aerosol Module: A size-segregated simulation of atmospheric aerosol processes for climate and air quality models 1. Module development, J. Geophys. Res., 108(D1), 4007, doi:10.1029/2001JD002002, 2003.

Guelle, W., Schulz, M., Balkanski, Y., and Dentener, F.: Influence of the source formulation on modeling the atmospheric global 
distribution of sea salt aerosol, J. Geophys. Res., 106, 27 509$27524,2001$.

Hebestreit, K., Stutz, J., Rosen, D., atveiv, V., Peleg, M., Luria, M., and Platt, U.: DOAS Measurements of Tropospheric Bromine Oxide in Mid-Latitudes, Science, 283, 55-57, 1999.

Hönninger, G. and Platt, U.: Observations of BrO and its vertical distribution during surface ozone depletion at Alert., Atmos. Environ., 36, 2481-2489, 2002.

Jöckel, P., Sander, R., Kerkweg, A., Tost, H., and Lelieveld, J.: Technical Note: The Modular Earth Submodel System (MESSy) - a new approach towards Earth System Modeling, Atmos. Chem. Phys., 5, 433-444, 2005,

http://www.atmos-chem-phys.net/5/433/2005/.

Jöckel, P., Tost, H., Pozzer, A., Brühl, C., Buchholz, J., Ganzeveld, L., Hoor, P., Kerkweg, A., Lawrence, M. G., Sander, R., Steil, B., Stiller, G., Tanarhte, M., Taraborrelli, D., van Aardenne, J., and Lelieveld, J.: The atmospheric chemistry general circulation model ECHAM5/MESSy1: consistent simulation of ozone from the surface to the mesosphere, Atmos. Chem. Phys., 6, 50675104, 2006,

http://www.atmos-chem-phys.net/6/5067/2006/.

Kerkweg, A., Buchholz, J., Ganzeveld, L., Pozzer, A., Tost, H., and Jöckel, P.: Technical Note: an implementation of the dry removal processes DRY DEPosition and SEDImentation in the Modular Earth Submodel System (MESSy), Atmos. Chem. Phys., 6, 4617-4632, 2006a.

Kerkweg, A., Sander, R., Tost, H., and Jöckel, P.: Technical Note: Implementation of prescribed (OFFLEM), calculated (ONLEM), and pseudo-emissions (TNUDGE) of chemical species in the Modular Earth Submodel System (MESSy), Atmos. Chem. Phys. Discuss., 6, 5485-5504, 2006b.

Kettle, A. and Andreae, M.: Flux of the dimethylsulfide from the ocean: A comparison of updated data sets and flux models, J. Geophys. Res., 105, 26 793-26 808, 2000.

Kohonen, H., Lehtinen, K., and Kulmala, M.: Multicomponent aerosol dynamics model UHMA: model development and validation, Atmos. Chem. Phys., 4, 757-771, 2004,

http://www.atmos-chem-phys.net/4/757/2004/.

Landgraf, J. and Crutzen, P. J.: An Efficient Method for Online Calculation of Photolysis and Heating Rates, J. Atmos. Sci., 55, 863-878, 1998.

Lauer, A., Hendricks, J., Ackermann, I., Schell, B., Hass, H., and Metzger, S.: Simulating aerosol microphysics with ECHAM/MADE GCM- Part I: Model description and comparison with observations, Atmos. Chem. Phys., 5, 3251-3276, 2005, http://www.atmos-chem-phys.net/5/3251/2005/.

Liss, P. S. and Merlivat, L.: Air-Sea Gas Exchange Rates: Introduction and Synthesis, in: The Role of Air-Sea Exchange in Geochemical Cycling, NATO ASI Series, edited by: BuatMénard, P., D. Reidel Publishing Company, Dordrecht, Netherlands, Vol. 185, pp. 113-127, 1986.

Metzger, S., Dentener, F., Pandis, S., and Lelieveld, J.: Gas/Aerosol partitioning: 1. A computationally efficient model, J. Geophys. Res., 107, doi:10.1029/2001JD001102, 2002.

Metzger, S., and Lelieveld, J.: Reformulating atmospheric aerosol thermodynamics and hygroscopic growth into haze and clouds, Atmos. Chem. Phys. Discuss., 7, 849-910, 2007, http://www.atmos-chem-phys-discuss.net/7/849/2007/.

Roeckner, E., Brokopf, R., Esch, M., Giorgetta, M., Hagemann,
S., Kornblueh, L., Manzini, E., Schlese, U., and Schulzweida, U.: Sensitivity of simulated climate to horizontal and vertical resolution in the ECHAM5 atmosphere model, J. Climate, 19, 3771-3791, 2006.

Sander, R.: Modeling atmospheric chemistry: Interactions between gas-phase species and liquid cloud/aerosol particles, Surv. Geophys., 20, 1-31, 1999.

Sander, R., Keene, W., Pszenny, A., Arimoto, R., Ayers, G., Baboukas, E., Cainey, J., Crutzen, P. J., Duce, R., Hönninger, G., Huebert, B., Maenhaut, W., Mihalopoulos, N., Turekian, V., and Dingenen, R. V.: Inorganic bromine in the marine boundary layer: a critical review, Atmos. Chem. Phys., 3, 1301-1336, 2003,

http://www.atmos-chem-phys.net/3/1301/2003/.

Sander, R., Kerkweg, A., Jöckel, P., and Lelieveld, J.: Technical Note: The new comprehensive atmospheric chemistry module MECCA, Atmos. Chem. Phys., 5, 445-450, 2005, http://www.atmos-chem-phys.net/5/445/2005/.

Sandu, A. and Sander, R.: Technical note: Simulating chemical systems in Fortran90 and Matlab with the Kinetic PreProcessor KPP-2.1, Atmos. Chem. Phys., 6, 187-195, 2006, http://www.atmos-chem-phys.net/6/187/2006/.

Sandu, A., Verwer, J. G., Blom, J. G., Spee, E., Carmichael, G. R., and Potra, F. A.: Benchmarking stiff ODE solvers for atmospheric chemistry problems II. Rosenbrock solvers, Atmos. Environ., 31, 3459-3472, 1997a.

Sandu, A., Verwer, J. G., van Loon, M., Carmichael, G. R., Potra, F. A., Dabdub, D., and Seinfeld, J. H.: Benchmarking stiff ODE solvers for atmospheric chemistry problems I. Implicit vs explicit, Atmos. Environ., 31, 3151-3166, $1997 \mathrm{~b}$.

Schulz, M., Balkanski, Y., Guelle, W., and Dulac, F.: Role of aerosol size distribution and source location in a threedimensional simulation of a Saharan dust episode tested against satellite-derived optical thickness, J. Geophys. Res., 103, 10 579-10 592, 1998.

Schwartz, S. E.: Chemistry of Multiphase Atmospheric Systems, vol. G6, chap. Mass-Transport Considerations Pertinent to Aqueous Phase Reactions of Gases in Liquid-Water Clouds, NATO ASI Series, pp. 415-471, 1986.

Solberg, S., Schmidbauer, N., Semb, A., Stordal, F., and Hov, Ø.: Boundary layer ozone depletion as seen in the Norwegian Arctic in spring, J. Atmos. Chem., 23, 301-332, 1996.

Spracklen, D. V., Pringle, K. J., Carslaw, K. S., Chipperfield, M. P., and Mann, G. W.: A global off-line model of size-resolved aerosol microphysics: I. Model development and prediction of aerosol properties, Atmos. Chem. Phys., 5, 2227-2252, 2005, http://www.atmos-chem-phys.net/5/2227/2005/.

Stier, P., Feichter, J., Kinne, S., Kloster, S., Vignati, E., Wilson, J., Ganzeveld, L., Tegen, I., Werner, M., Balkanski, Y., Schulz, M., and Boucher, O.: The Aerosol-Climate Model ECHAM5-HAM, Atmos. Chem. Phys., 5, 1125-1156, 2005, http://www.atmos-chem-phys.net/5/1125/2005/.

Tost, H., Jöckel, P., Kerkweg, A., Sander, R., and Lelieveld, J.: Technical note: A new comprehensive SCAVenging submodel for global atmospheric chemistry modelling, Atmos. Chem. Phys., 6, 565-574, 2006, http://www.atmos-chem-phys.net/6/565/2006/.

Tost, H., Jöckel, P., Kerkweg, A., Pozzer, A., Sander, R., and Lelieveld, J.: Global cloud and precipitation chemistry 
and wet deposition: tropospheric model simulations with ECHAM5/MESSy1, Atmos. Chem. Phys., 7, 2733-2757, 2007, http://www.atmos-chem-phys.net/7/2733/2007/.

Vignati, E., Wilson, J., and Stier, P.: M7: An efficient size-resolved aerosol microphysics module for large-scale aerosol transport, J. Geophys. Res., 109, D22 202, doi:10.1029/2003JD004486, 2004.

von Glasow, R., Sander, R., Bott, A., and Crutzen, P. J.: Modeling halogen chemistry in the marine boundary layer 1 . Cloudfree MBL, J. Geophys. Res., 107, doi:10.1029/2001JD000942, 2002a.

von Glasow, R., Sander, R., Bott, A., and Crutzen, P. J.: Modeling halogen chemistry in the marine boundary layer 2 . Interactions with sulfur and the cloud-covered MBL, J. Geophys. Res., 107, 4323, doi:10.1029/2001JD000943, 2002 b.
Warneck, P.: The relative importance of various pathways for the oxidation of sulfur dioxide and nitrogen dioxide in sunlit continental fair weather clouds, Phys. Chem. Chem. Phys., 1, 54715483, 1999.

Wayne, R. P.: Chemistry of Atmospheres, Oxford University Press, 2000.

Wilson, T. R. S.: Salinity and the major elements of sea water, in: Chemical Oceanography, Vol. 1, 2nd Ed., edited by: Riley, J. P. and Skirrow, G., Academic Press, pp. 365-413, 1975. 